\title{
Neuropublicidad gráfica. Innovador método analítico del proceso comunicativo de la publicidad visual
}

\author{
José Jesús VArgas Delgado \\ Universidad Europea de Madrid \\ jjesus.vargas@uem.es
}

Recibido: $27 / 11 / 2012$

Aceptado: 23/01/2013

\begin{abstract}
Resumen
Nuestra investigación se encuentra focalizada en los efectos de un estudio experimental en el que examina en profundidad la deconstrucción de la comunicación publicitaria visual (gráfica y digital) eficiente. Definición de la esencia constructiva de los mensajes comunicativos visuales. Para ello hemos desarrollado un método analítico de deconstrucción de la eficiencia comunicativa aplicada a los mensajes publicitarios gráficos. Una deconstrucción perceptiva donde las piezas fundamentales son: atención, memoria, percepción, comprensión, retórica y persuasión, lectura y área de condensación semántica. Son 7 pilares neurálgicos de nuestra deconstrucción analítica en el marco de la comunicación publicitaria gráfica y digital.
\end{abstract}

Palabras clave: neuroadvertising, atención, memoria, comunicación publicitaria visual y condensación semántica.

\section{Neuroadvertising Graphics. Innovative Process Analytical Method Communicative Visual Advertising}

\begin{abstract}
Our research is focused on the effects of an experimental study that examines in depth deconstruction of visual advertising communication (graphic and digital) efficient. Constructive definition of the essence of visual communication messages. We have developed an analytical method of deconstruction of communicative efficiency applied to advertising graphics. A perceptive deconstruction where the building blocks are: attention, memory, perception, understanding, rhetoric and persuasion, reading and semantic condensation area. There are seven pillars of our analytical deconstruction nerve within the graphic and digital marketing communication.
\end{abstract}

Keywords: neuroadvertising, attention, memory, visual and condensation advertising communication semantics

\section{Referencia normalizada}

VARGAS DELGADO, José Jesús (2013): "Neuropublicidad gráfica. Innovador método analítico del proceso comunicativo de la publicidad visual". Estudios sobre el mensaje periodístico. Vol. 19. Núm. especial abril, págs.: 1057-1065. Madrid, Servicio de Publicaciones de la Universidad Complutense.

Sumario: 1. Introducción. 2. Metodología. 3. Desarrollo; 3.1. Tipos de lectura; 3.2. Estructura de enfoque; 3.3. Reparto de espacios; 3.4. Balanza de espacios visuales; 3.5. Área de condensación semántica; 3.6. Presencia de imagen versus texto; 3.7. Nivel de iconicidad; 3.8. Grado de textura; 3.9. Dirección de la pieza; 3.10. EE/EI Elementos explícitos -Elementos implícitos.4. Conclusiones. 5. Referencias bibliográficas

\section{Introducción}

Definición de la esencia constructiva de los mensajes comunicativos visuales. Una aplicación neuropublicitaria para detectar y entender los principales engranajes inter- 
nos que intervienen en la percepción de los mensajes publicitarios en la esfera visual. Un análisis que se puede aplicar tanto a la publicidad gráfica como a los mensajes publicitarios en la esfera digital. Para ello hemos desarrollado un método analítico de deconstrucción de la eficiencia comunicativa aplicada a los mensajes publicitarios gráficos. Una deconstrucción perceptiva donde las palancas fundamentales son 10: tipos de lectura, estructura de enfoque, reparto de espacios, balanza de espacios visuales, área de condensación semántica, porcentaje presencia de imagen versus texto, nivel de iconicidad, grado de textura, dirección de la pieza, estímulos implícitos y explícitos. Son 10 pilares neurálgicos de nuestra deconstrucción analítica en el marco de la comunicación publicitaria gráfica y digital. En este sentido, el tiempo y el espacio, se conforman como las variables funcionales que permiten que las 10 palancas en la construcción de los mensajes publicitarios gráficos alcancen niveles máximos de optimización y productividad. El tiempo y el espacio se convierten en interruptores de ecualización, que permiten a las 10 claves, mencionadas anteriormente, que el mensaje suene a la perfección, afinado y eficiente, desde una perspectiva publicitaria expresada en imagen. Deconstrucción metodológica, que se conforma como un método docente, e innovador, en el análisis y construcción de los mensajes publicitarios básicos. El objetivo de este artículo sobre este método innovador, está posicionado en el desarrollo de las principales inferencias y conclusiones cualitativas y cuantitativas en la deconstrucción analítica de la comunicación publicitaria gráfica. A través de un estudio multifactorial, realizamos un exhaustivo análisis de todas las variables definidas para obtener ilimitadas conclusiones e inferencias, que permiten esclarecer tendencias de valor cuantitativos y cualitativos de máxima eficiencia en la construcción de la comunicación publicitaria visual. Resultados de contenidos que plantean una nueva fórmula docente para la creación y análisis de la comunicación publicitaria visual contemporánea. 10 factores eficientes en la comunicación publicitaria gráfica y visual.

\section{Metodología}

Para llevar a cabo este análisis vamos a poner en marcha un análisis cuantitativo. Nuestra estrategia consiste en investigar empírica y cuantitativamente los diferentes elementos, que nos permitan alcanzar nuestro estudio. Seleccionamos el cuestionario para analizar los factores de eficiencia en la comunicación publicitaria gráfica. En nuestra investigación hemos optado por utilizar la encuesta personal con la asistencia del entrevistador. Dentro de las técnicas de carácter neuropublicitario hemos optado por utilizar el taquitoscopio. Esta medida recibe el nombre del mecanismo en que se basa su aplicación, consiste en la utilización de un aparato de tipo óptico que permite proyectar en una pantalla cualquier tipo de pieza publicitaria, y mide la rapidez con que un individuo puede percibir y comprender determinadas imágenes o textos a los que ha estado expuesto. El procedimiento consiste en proyectar las imágenes o textos del estímulo publicitario en intervalos variables de tiempo, comenzando por períodos de tiempo muy pequeños de proyección (pudiendo incluso llegar a exposiciones inferiores a 1/1000 segundos) y aumentándolos progresivamente, a fin de poder determinar el tiempo mínimo de exposición para que el individuo pueda percibir algún detalle del anuncio proyectado.Beerli, A. y Martín, J.D., 1999: 159). 
Esta técnica resulta de gran utilidad en situaciones en las que se desea testar determinadas formas de publicidad visual, tales como carteles, materiales en el punto de venta y envases, en las que la legibilidad de elementos como el nombre y el color resultan muy importantes. Especialmente interesante su aplicación al campo de la comunicación publicitaria digital (internet, dispositivos móviles, tablets, ...). De esta manera sus condiciones óptimas de aplicación se ajustan perfectamente a nuestra investigación dado que nuestro test se centra en la eficiencia comunicativa de publicidad gráfica. Con carácter general, las principales aplicaciones de esta medida al campo publicitario se centran en:

- Determinar las partes que se perciben mejor de un anuncio.

- Conocer las características de las letras de más fácil percepción.

- Identificar la posición más adecuada para el elemento del anuncio que más interese.

- Comparar el grado de percepción de las diferentes alternativas de anuncios a una determinada velocidad.

- Determinar el tiempo necesario de exposición para la percepción total o parcial del anuncio.

- Conocer si las prioridades establecidas por el anunciante se adecuan a las asimiladas por los sujetos.

\section{Desarrollo}

\subsection{Tipos de lectura}

Analizamos en este parámetro el itinerario visual de nuestra mirada a lo largo de la pieza. Después de las conclusiones de nuestra investigación la clasificación de los tipos de lecturas son 4. A continuación, analizamos cada uno de los tipos lecturas.

- Lectura convencional: El itinerario de configuración de la mirada en la lectura visual es natural, y cumple con las expectativas visuales e inconscientes del receptor. Los principales efectos a corto plazo en el cerebro del recpetor se focalizan sobre la baja implicación del receptor, atención baja, comprensión alta y memoria media-baja. Las piezas de lectura convencional y tradicional tienen el principal objetivo de informar y llegar al receptor de una forma nítida sin ofrecerle demasiadas posibilidades de concluir mentalmente la narración del receptor. Cómoda percepción, mínima estimulación de la memoria.

- Lectura condicionada. La lectura condicionada lo que hace es romper la lectura natural de las piezas. El receptor no puede continuar con su lectura natural de izquierda a derecha y de superior a la parte inferior, y rompe la tendencia inconsciente de lectura de las piezas gráficas. A medida que fragmentemos más la dirección natural de la lectura convencional, la pieza estará más condicionada y requerirá mayores cotas de implicación mental y de memoria en el receptor.

- Lectura vacía: generación de incógnita significativa. El itinerario de nuestra mirada se expone a una bifurcación en la cual tiene que elegir una ramificación u otra. Los principales efectos son aumento ostensible de atención, comprensión muy baja y memoria alta.

- Multilectura: plena implicación / posibilidad de dispersión del objetivo. Atención muy alta, comprensión muy baja, memoria muy alta. 
Después de analizar nuestra muestra de investigación de las piezas desde 1993 hasta 2012, podemos percibir que una gran mayoría de las piezas gráficas tienen una estructura condicionada. Y a medida que avanzan los años, las piezas con lectura convencional, van disminuyendo para dejar paso a las piezas con lectura condicionada.

\subsection{Estructura de enfoque}

El criterio de la estructura de enfoque nos va a permitir analizar las piezas desde una perspectiva de volumen de herramientas conceptuales para entender las piezas. A medida que necesitemos más elementos gráficos en la composición de la pieza para obtener el objetivo comunicativo elegido, la pieza será más argumental. Es un análisis pseudocuantitativo. A medida que el número de elementos sea menor la estructura será evidente. Es un criterio de significado que tiene una relación directa con la lectura de la pieza.

- Argumental. Máximo de herramientas. Mensaje caliente e implicador. Con efectos directos en atención alta, comprensión baja y memoria muy alta.

- Evidencia. Mínimo de herramientas, máxima significación polisémica. Mensaje frío y pasivo. Atención baja, comprensión muy alta y memoria baja.

Después de analizar nuestra muestra de investigación de las piezas desde 1993 hasta 2012, podemos percibir que una gran mayoría de las piezas gráficas tienen una estructura de enfoque argumental. Aunque si repasamos los datos obtenidos podemos percibir que a medida que avanzan los años las piezas con estructura argumental dejan paso a las evidentes debido al escaso tiempo que el receptor invierte y dispone en la interiorización de las piezas publicitaria gráficas. Una muestra evidente que en la publicidad digital, especialmente en los nuevos dispositivos móviles tenemos que buscar a rentabilizar el mensaje publicitario con mensajes que desemboquen en un alto nivel de atención y memorización.

\subsection{Reparto de espacios}

- Simetría: equilibrio estético con facilidad para la asimilación. Los efectos son los siguientes: atención baja, comprensión alta, memoria muy baja.

- Asimetría: asimilación por divergencia estética. Atención alta o muy alta (dependiendo del tipo de asimetría). Comprensión alta (dependiendo del tipo de asimetría). Memoria muy baja (dependiendo del tipo de asimetría).

Después de analizar nuestra muestra de investigación de las piezas desde 1993 hasta 2012, podemos percibir que una gran mayoría de las piezas gráficas tienen un reparto de espacios asimétrico. Aunque si repasamos los datos obtenidos podemos percibir que a medida que avanzan los años las piezas con estructura simétrica dejan paso a las estructuras asimétricas. El receptor se siente mucho más implicado comunicativamente en las piezas asimétricas.

\subsection{Balanza de espacios visuales}

El concepto de balanza de espacios visuales mide el nivel de saturación imagen-texto de la piezas publicitarias. Cuando las piezas tienen más de un 50\% cuantitativamente 
de imagen sobre el fondo, la pieza es estructurada. Por debajo del $50 \%$ la pieza tiene una balanza desequilibrada.

- Equilibrio de espacios. Aglomeración de información, baja participación del receptor. Atención baja, comprensión alta. Memoria muy baja.

- Desequilibrio de espacios. Relajada información visual. atención alta o muy alta (dependiendo del tipo de equilibrado), comprensión alta (dependiendo del tipo de equilibrado), memoria muy baja (dependiendo del tipo de equilibrado).

Las piezas desequilibradas son mucho más proclives a que se produzca crowdsourcing. Mucha mayor externalización de los significados de marca. (García Carrizo, Jennifer, 2012: web).

Después de analizar nuestra muestra de investigación de las piezas desde 1993 hasta 2012, podemos percibir que una gran mayoría de las piezas gráficas tienen una balanza equilibrada. Aunque si repasamos los datos obtenidos podemos percibir que a medida que avanzan los años las piezas con estructura equilibrada dejan paso a las estructuras desequilibradas.

\section{5. Área de condensación semántica}

Capacidad del mensaje para agrupar en un porcentaje determinado el sentido comunicativo de cada pieza. Es el umbral mínimo de significado que podemos omitir, manteniendo la esencia comunicativa. A medida que superemos el 30\% de condensación espacial semántica, la pieza comienza a debilitar su óptima definición de área de condensación semántica, significado, comprensión, síntesis y de forma indirecta su eficiencia publicitaria. Hasta que umbrales estéticos de una pieza somos capaces de recortar, manteniendo el significado de la pieza.

Las piezas que son capaces de concentrar en un área de significado comprimido de $30 \%$ o menos, consiguen tener unos niveles de atención y memoria por encima de la media. El riesgo comunicativo reside en la comprensión, dado que a medida que salgamos de la zona de confort creativa y sometamos al receptor a un juego interactivo polisémico de esta naturaleza, podemos estar expuestos a que nuestro mensaje no llegue al receptor.

No debemos extremar la minimización del área de condensación semántica dado que podemos desvirtuar la comunicación corporativa de la marca. (Gómez Nieto, Begoña; Tapia Frade, Alejandro y Díaz Chica, Óscar, 2012: web)

Después de analizar nuestra muestra de investigación de las piezas desde 1993 hasta 2012, podemos percibir que una gran mayoría de las piezas gráficas tienen un área de condensación semántica demasiado amplias. Aunque si repasamos los datos obtenidos podemos percibir que a medida que avanzan los años las piezas con área de condensación semántica óptima va ganando protagonismo cuantitativo.

\subsection{Presencia de imagen versus texto}

Porcentaje de presencia de imagen y texto.

Medimos a través de esta calibración la presencia de la imagen, texto y espacio vacío en una pieza gráfica. Nuestro cerebro se siente más estimulado y exigido con las 
piezas que tienen un espacio vacío. En cambio a medida que la presencia del texto y la imagen sea más amplia los efectos de imaginación y memoria por el receptor serán menores, en cambio las implicaciones de la comprensión alcanzarán cotas más altas.

Después de analizar nuestra muestra de investigación de las piezas desde 1993 hasta 2012, podemos percibir que una gran mayoría de las piezas gráficas tienen a una mayor preponderancia de la imagen y menos del texto. Si repasamos los datos obtenidos podemos percibir que a medida que avanzan los años las piezas con zona vacía va obteniendo protagonismo, dado que los receptores demandan una zona de relajación visual para estimular y aumentar la imaginación del perceptor.

\subsection{Nivel de iconicidad}

Nivel de acercamiento o lejanía de la imagen reflejada con la imagen real.

El receptor se siente cómodo y naturalmente implicado, cuando los estímulos elegidos tienen una relación directa con la realidad que representan. Corresponden con niveles de iconicidad bajos. En cambio en las piezas en las que la utilización de una imagen sea mucho más alejada de la realidad, los niveles de iconicidad con altos. El efecto inmediato es que las piezas con niveles de iconicidad altos estimulan notablemente la memoria del receptor. Aspectos que mejoran ostensiblemente la memoria.

Después de analizar nuestra muestra de investigación de las piezas desde 1993 hasta 2012, podemos percibir que una gran mayoría de las piezas gráficas tienen una mayor preponderancia del nivel de iconicidad por encima del nivel 6. Si repasamos los datos obtenidos podemos percibir que a medida que avanzan los años las piezas tienen un mayor nivel de iconicidad, lo que demuestra la tendencia a la madurez estética.

\subsection{Grado de textura}

La mayor parte de nuestra experiencia es óptica y no es táctil. Resultado de un aprendizaje cultural que nos ha llevado a no tocar las cosas y/o las personas, por lo que la evaluación de la textura se ha convertido progresivamente en netamente visual. Nuestra investigación ha concluido una clasificación estratificada de cuatro categoría: suavidad, frialdad, aspereza y quietud.

La opción que tomemos debe reflejar verdaderamente el carácter sensorial y la personalidad de nuestra marca. Después de analizar nuestra muestra de investigación de las piezas desde 1993 hasta 2012, podemos percibir que existe un reparto homogéneo entre las cuatro texturas. Si repasamos los datos obtenidos podemos percibir que a medida que avanzan los años las piezas tienen un mayor nivel de utilización de la textura quietud. Una tendencia natural con la publicidad más emocional o espiritual, por encima de la publicidad racional y sensorial.

\subsection{Dirección de la pieza}

Vertical-horizontal / diagonal / circular.

Efectos: Atención baja estable, comprensión alta serenidad y poco provocador, memoria muy baja.

Atención media-alta inestable comprensión media-baja actividad y provocador dinámica y memoria media. 
Atención condicionada, comprensión condicionada falta de confianza, emotividad y memoria media.

Después de analizar nuestra muestra de investigación de las piezas desde 1993 hasta 2012, podemos percibir que existe una mayor representación de las piezas con direcciones verticales-horizontales. Aunque si repasamos los datos obtenidos podemos percibir que a medida que avanzan los años las piezas van tendiendo a una estructura diagonal y circular. Una clara muestra de la madurez en la conexión con los receptores.

\subsection{EE/EI Elementos explícitos -Elementos implícitos}

EI: Estímulos visuales que aparecen en el anuncio que están lejanamente relacionado con el producto publicitario. EE: Estímulos visuales que aparecen en el anuncio que están directa y cercanamente relacionados con el producto publicitado.

Las piezas con elementos visuales explícitos favorecen la comodidad perceptiva de la pieza, pero disminuye la atención. Por el contrario las piezas implícitas, que someten al receptor a una obligada participación de significados metafóricos dado que mantienen una evidente lejanía entre la imagen y lo publicitado, generarían una mayor permanencia en la mente del receptor. Una lejanía narrativa que permite una máxima invitación al receptor a finalizar y estimular su memoria y atención. Por el contrario la comprensión se ve sensiblemente deteriorada. Corresponde al publicitario el encuentro de la sutil y delicada línea que separa la virtud estética entre la comprensión y la atención con el prisma de los elementos implícitos y explícitos.

Después de analizar nuestra muestra de investigación de las piezas desde 1993 hasta 2012, podemos percibir que una gran mayoría de las piezas gráficas tienen una mayor preponderancia de los elementos explícitos. Aunque si repasamos los datos obtenidos podemos percibir que a medida que avanzan los años las piezas con elementos implícitos van obteniendo protagonismo cuantitativo.

\section{Conclusiones}

Consideramos las 10 palancas anteriores como esenciales para conseguir la conexión con el dispositivo del receptor. Después de analizar intensamente los anteriores 10 parámetros gráficos, tenemos en nuestras manos una aplicada herramienta metodológica para poder ecualizar a nuestro antojo, y deseo del patrocinar, o anunciante, la estrategia de comunicación y ejecución creativa. Una herramienta metodológica bidimensional que permite constituirse como, en primera instancia y con un filtro académico analítico y semántico, un instrumento para analizar las piezas una vez creadas. Por otro lado, permite constituirse como un utensilio que despierta y eleva cualitativamente nuestro nivel de consciencia a la hora de crear, diseñar y configurar una pieza midiendo milimétrica y deliberadamente una serie de efectos deseados comunicativos. Las posibilidades metodológicas que se presentan son infinitas. Se conforma como vital que los nuevos estudiantes del grado en Comunicación Publicitaria consideren estos elementos como una forma de interiorizar los elementos esenciales a la hora de crear los mensajes publicitarios. Y crea un nuevo mundo de la creación gráfica que puede elevar sus intereses por este sector profesional de la profesión. (Ortiz Sobrino, Miguel Ángel; Rodríguez Barba, Dolores; y Pérez Serrano, María José, 2011: web). 
En este artículo simplemente hemos dejado esbozado los principales microfactores que influyen en la atmósfera ilimitada de cada variable. Se abre, por lo tanto, un nuevo, y mágico, escenario de aplicación que en próximas y deseadas investigaciones tenemos pensado aplicar a la esfera digital.

\section{Referencias bibliográficas}

BASSAT, Luis (2001): El libro Rojo de la Publicidad. Barcelona, Plaza \& James Editores.

BENAVIDES DELGADO, Juan (1994): La crisis de la publicidad. Madrid, Editorial Comunicación 2000.

BUNGE, Mario (1981): La investigación cientifica. Barcelona, Ariel.

CALDEVILLA DOMINGUEZ, David (2004): Relaciones Públicas y su fundamentación. Madrid, Vision Net.

CLEMENTE, Miguel y SANTALLA, Zuleyma (1991): El documento persuasivo. Universidad Complutense de Madrid. Bilbao, Ediciones Deusto S.A.

GARCÍA CARRIZO, Jennifer (2012): "Crowdsourcing y publicidad: una aplicación desde el punto de vista de la marca". Revista de Comunicación Vivat Academia, ${ }^{\circ}$ 120, septiembre 2012. Madrid, Universidad Complutense. En: http://www.ucm.es /info/vivataca/numeros/n120/DATOSS120.htm [Consultado: 4 de noviembre de 2012]

GÓMEZ NIETO, Begoña; TAPIA FRADE, Alejandro; y DÍAZ CHICA, Óscar (2012): "La comunicación corporativa a través de las páginas web: el caso de las ONGs españolas". Revista de Comunicación Vivat Academia, n 120, septiembre 2012. Madrid, Universidad Complutense, en: http://www.ucm.es/info/vivataca/numeros /n120/DATOSS120.htm [Consultado: 4 de noviembre de 2012]

JOANNIS, Henri (1992): El proceso de creación Publicitaria, Planteamiento, concepción y realización de los mensajes. Bilbao, Ediciones Deusto

JOANNIS, Henri (1996): La creación Publicitaria desde la Estrategia de Marketing. Bilbao, Ediciones Deusto.

LEÓN, José Luis (1996): Los efectos de la publicidad. Madrid, Ariel.

MOLINÉ, Marçal (2003): La comunicación activa. Publicidad sólida. Barcelona, Deusto.

ORTIZ SOBRINO, Miguel Ángel; RODRÍGUEZ BARBA, Dolores; y PÉREZ SERRANO, María José (2011): "Perfil de entrada de los futuros alumnos de comunicación en las universidades de Madrid, en 2010/2012: la reafirmación de los rasgos". Revista de Comunicación SEECI, n 26, noviembre 2011. Madrid, Universidad Complutense: http://www.ucm.es/info/seeci/Numeros/Numero 26 /DATOS.html [consultado: 4 de noviembre de 2012]

VARGAS, José Jesús (2012): Análisis de la Comunicación publicitaria gráfica: Deconstrucción de la eficiencia comunicativa gráfica: innovador método docente en el análisis y construcción de los mensajes publicitarios. Madrid, Vision Libros. 
ZUNZUNEGUI, Santos (1984): Mirar la imagen. Bilbao, Universidad del País Vasco.

\section{José Jesús VARGAS DELGADO}

Universidad Europea de Madrid

Facultad de Artes y Comunicación

Director del Departamento de Publicidad y Contenidos

jjesus.vargas@uem.es 